\title{
Lançamento de Projéteis de Brinquedo: modelagem matemática e experimentação investigativa
}

\author{
Launch of Toy Projectiles: mathematical modeling and investigative \\ experimentation
}

\author{
$\begin{array}{lll}\text { L. F. A. } \mathrm{Melo}^{1} \text {, A. C. L. Moreira } & \text {, } & \text { G. Camelo-Neto*2 }\end{array}$ \\ ${ }^{1}$ Núcleo de Formação Docente, Universidade Federal de Pernambuco. \\ ${ }^{2}$ Núcleo Interdisciplinar de Ciências Exatas e da Natureza, Universidade Federal de \\ Pernambuco.
}

\begin{abstract}
Resumo
O estudo do lançamento de projéteis em diferentes níveis de ensino está baseado numa mode-lagem teórica simplificada, onde o projétil é abstraído em uma partícula movendo-se em duasdimensões $e$, normalmente, não sujeito ao efeito resistivo do ar. Neste trabalho, é apresentadauma proposta experimental simples, envolvendo a utilização de brinquedos de baixo custo, como objetivo de implantar atividades investigativas em sala de aula, despertando uma postura crí-tica acerca dos modelos teóricos estudados. Como forma de demostrar o relacionamento entre amodelagem teórica-matemática e a experimentação, é realizada uma revisão detalhada de doisdos modelos teóricos existentes para o lançamento oblíquo de uma partícula: o modelo padrãosem resistência do ar e o modelo sujeito a uma força de arrasto linearmente proporcional à veloci-dade da partícula. No primeiro modelo é utilizada a estratégia usual, utilizando-se a cinemáticavetorial, no segundo, são desenvolvidas as equações do movimento a partir das leis de Newton, as quais são resolvidas exatamente. Em ambos os casos, são obtidas expressões analíticas para oalcance dos projéteis em função do ângulo de lançamento - e do coeficiente de resistência do arno segundo modelo. Além da comparação e discussão entre os resultados dos modelos matemáti-cos, é proposta uma abordagem experimental investigativa de baixo custo para o lançamento deprojéteis reais, utilizando brinquedos. Nessa oportunidade, estudantes são desafiados a levantarconcepções espontâneas acerca da validade do modelo matemático sem resistência do ar, ao qualforam expostos previamente em sala de aula. Finalmente, os estudantes são apresentados aosresultados do modelo com resistência da ar, sem serem mostrados necessariamente os detalhesdo desenvolvimento matemático, sendo feitas considerações a respeitos de alguns dos melhora-mentos. Por fim, são apresentadas evidências acerca da eficiência da atividade investigativa nacompreensão sobre o que seja um modelo matemático e sua relação com a realidade.
\end{abstract}

Palavras-chave: Ensino de Física, Laboratório Semi-Aberto, Experimentação de Baixo Custo.

*gustavo.camelont@ufpe.br 


\begin{abstract}
Studies on projectile launching at various educational levels are based upon simplified theoreticalmodels. We abstract the projectile as a particle moving in two dimensions and not subjected tothe resistive force of the air. In this work, we propose a simple experimental procedure involvinglow-cost toys, whose main objective is to implement investigative activities in the classroom,awakening a critical posture about the theoretical models studied. We carry out a detailedreview of two existing academic models for the oblique launching of a particle to demonstratethe relationship between mathematical modelling and experimentation: the standard modelwith no air resistance and the model subject to a drag force proportional to the particle velocity. We employed the usual strategy by solving the first model through vectorial kinematics whiledeveloping the equations of motion directly from Newton's laws and solving them exactly forthe second. We obtained, particularly, analytical expressions for the range of the projectiles asa function of the parameters to both models. Beyond comparing and discussing the results ofthe mathematical models, a low-cost investigative experimental approach is proposed for realprojectiles launching using toys. During this procedure, we challenged the students to raisespontaneous conceptions about the validity of the model with no air resistance they had beenpreviously presented in the classroom. Subsequently, we exhibit the results from the modelwith air resistance to the students, not necessarily explaining the details of the mathematicaldevelopment, making considerations about some of the improvements. Ultimately, pieces ofevidence are displayed about the efficiency of investigative activities in the understanding ofwhatever a mathematical model is and its relationship with reality.
\end{abstract}

Keywords: Physics Teaching, Semi-Open Laboratory, Low Cost Experimentation.

\title{
I. INTRODUÇÃO
}

O estudo do movimento dos corpos tanto nos últimos anos do ensino médio quanto nos períodos iniciais dos cursos superiores de Ciências, Licenciaturas e Engenharias está baseado em modelos simplificados. Os corpos são abstraídos e tratados como partículas pontuais [Greiner 2004] que nada mais são do que entidades matemáticas sem dimensão. Além do mais, forças resistivas são desprezadas, como é o caso das forças de interação com o ar e outras deixadas para um estudo posterior, como é o caso da força de atrito de superfície. Esta, por sua vez, também simplificada como sendo uma força cuja intensidade é proporcional à intensidade da força normal, podendo comparecer como atrito estático caso em que não há deslizamento entre as superfícies de contato - ou como atrito dinâmico (ou cinético), caso em que há deslizamento relativo entre as superfícies de contato [Halliday, Resnick e Walker 2016, Lemos 2007].

Evocam-se questões didáticas como a principal razão para essas simplificações uma vez que a introdução da resistência do ar torna o estudo do modelo matemático correspondente impraticável sem que os estudantes possuam determinados pré-requisitos como, por exemplo, técnicas de solução de equações diferenciais [Thormton e Marion 2011]. A completa omissão da resistência do ar pode deixar como legado a impressão de que apenas modelos 
sem as forças resistivas sejam tratadas pela Física. Tal fato faz com que o estudante possa eventualmente tomar como verdade inconteste as previsões dos modelos não-resistivos em suas visões de mundo de modo a tornar indistinguível, teoria e realidade [Bunge 2009].

É possível, contudo, adicionar uma análise menos idealizada do movimento dos corpos através de recursos de animação numérica ou demonstrações experimentais, sem que haja um desenvolvimento pormenorizado de modelos teóricos mais avançados, porém apresentando-os ainda que de forma qualitativa em etapas iniciais nos estudos sobre o movimento dos corpos.

Matemática é a linguagem utilizada pelos Físicos para expressar as diversas leis e fenômenos da natureza. Sem a matemática seria extremamente trabalhoso descrever qualquer fenômeno utilizando apenas palavras e figuras. Em relação a essa correlação entre matemática e física, Bassanezi [Bassanezi 2002] afirma que:

A Matemática para as ciências exatas, principalmente a Física, é uma ferramenta insubstituível, já que proporciona a elaboração de modelos matemáticos que: resultam da interpretação dos problemas que expressam situações, que representam fenômenos físicos mostrando assim que há uma forte relação entre a Matemática e a Física. O objetivo fundamental do "uso"de matemática é de fato extrair a parte essencial da situação-problema e formalizá-la em um contexto abstrato onde o pensamento possa ser absorvido com uma extraordinária economia de linguagem. Desta forma, a matemática pode ser vista como um instrumento intelectual capaz de sintetizar ideias concebidas em situações empíricas que estão quase sempre camufladas num emaranhado de variáveis de menor importância. ( [Bassanezi 2002], p.18).

Esta estreita ligação entre a Física e a Matemática assume papéis complementares, passando esta a ser um instrumento de conceituação dos conteúdos científicos, emprestandolhes mais consistência e, por vezes, atuando mais do que um simples modelo. Dessa forma, acreditamos que o trabalho de tentar transformar fenômenos naturais em problemas matemáticos através da criação de modelos teóricos, resolvê-los e validá-los, consiste na melhor maneira de não apenas explorar a indissociabilidade entre física e matemática, como evitar o realismo ingênuo mediante uma postura crítica acerca dos modelos teóricos estudados.

Diante do exposto, o presente trabalho apresenta uma proposta experimental simples, com brinquedos de baixo custo que produz bons resultados - no sentido de que modelos teóricos são corroborados pelos dados experimentais - para o movimento de um projétil em duas dimensões (lançamento oblíquo) com resistência do ar, bem como a modelagem matemática, desenvolvida de forma pormenorizada em dois níveis: com e sem resistência do ar. Entretanto, propor atividades experimentais com brinquedos de baixo custo por si só não basta: devemos inseri-las em um contexto educacional [Brandão, Araujo e Veit 2011], sem o qual estaremos reproduzindo metodologias arcaicas sob nova roupagem (experimentos com brinquedos). Portanto, este trabalho consiste também em aplicar, em caráter de demonstração investigativa [Carvalho 2014], os experimentos supracitados em 
uma turma de ensino médio que já se deparou com o conteúdo 'lançamento obliquo sem resistência do ar'. Com essa etapa (demonstração investigativa) pretende-se levantar concepções espontâneas acerca da validade deste modelo teórico (sem resistência do ar) pelos estudantes. De posse desse resultado, discutiremos uma proposta de implementação de atividades experimentais em caráter aberto [Carvalho 2014] envolvendo os efeitos de resistência do ar.

De forma sucinta, pretende-se criar um exemplar [Kuhn 2013] acerca de como implantar atividades investigativas em sala de aula. Para isso, o presente trabalho terá a seguinte estrutura: primeiro será feito um paralelo entre o modelo teórico sem resistência do ar e o resultado do experimento aqui proposto, à luz do modelo com resistência do ar. Análises gráficas e computacionais serão utilizadas, mostrando em quais casos o modelo ultrasimplificado sem resistência do ar se adapta bem ao experimento e em quais casos o modelo falha consideravelmente. Na seção II serão introduzidos os modelos teóricos com e sem resistência do ar, sendo discutidas suas principais características e principais previsões teóricas. Na seção III a metodologia experimental é apresentada, juntamente com o equipamento utilizado; são apresentados, também, os dados obtidos para o alcance dos projéteis, especificamente para o alcance em termos do ângulo de lançamento. Na seção IV , apresentaremos uma proposta metodológica de caráter semi-aberto [Carvalho 2014] correlacionando atividades experimentais com modelagem matemática em uma proposta investigativa. Finalmente, na seção V são apresentadas nossas conclusões e quais nossas perspectivas para a continuação deste trabalho.

\section{Modelos Teóricos}

Nesta seção discutiremos, rapidamente, os modelos de partícula sem resistência e com resistência viscosa linear (proporcional à velocidade), para posterior comparação com os resultados experimentais. De maneira geral, o modelo para o movimento de um projétil sem a resistência do ar poderia ser desenvolvido a partir das leis de Newton [Halliday, Resnick e Walker 2016, Thormton e Marion 2011], contudo, por causa de sua simplicidade, seja tratado no contexto da cinemática vetorial, utilizando os conceitos de movimento retilíneo e uniforme (MRU) para a componente horizontal da posição e de movimento retilíneo uniformemente variado (MRUV) para a componente vertical da posição. O modelo para o movimento sob resistência viscosa do ar, entretanto, não compartilha a mesma simplicidade. Mesmo em sua formulação mais simples, a resistência do ar é introduzida como uma força proporcional à velocidade do projétil, de modo que a aceleração se torna função da velocidade, inviabilizando uma resolução da equação do movimento [Thormton e Marion 2011] sem conhecimentos de equações diferenciais. As técnicas matemáticas necessárias para se analisar modelos mais realistas, envolvendo resistência viscosa do ar, momento de inércia, rotação, entre outras, são desafiadoras mesmo para cursos de nível superior, inclusive algumas das técnicas envolvendo movimento viscoso e hidrodinâmica são abordadas apenas em cursos específicos de pós-graduação. No que segue, os pormenores da formulação e da solução dos modelos sem e com resistência do ar serão apresentados. 


\section{II.1. Modelo sem Resistência do Ar}

O modelo mais simples para lançamento de projeteis é baseado no movimento de uma partícula sujeita apenas à força de atração gravitacional constante e uniforme, desprezandose por total a resistência do ar. Por se tratar de uma partícula, não há qualquer outro grau de liberdade, apenas os graus de liberdade de translação, sendo consideradas apenas duas dimensões. O modelo é simples e bem conhecido, contudo, iremos detalhar seus resultados aqui como uma maneira didática de introduzir os conceitos relevantes.

Como apenas o peso do projétil é considerado, não há componente horizontal para a aceleração, logo, a componente horizontal da posição do projétil se comporta como a de uma partícula que se desloca em MRU. Por outro lado, a ação do peso impõe uma aceleração vertical e para baixo, dessa forma, a componente vertical da posição do projétil se comporta como a de uma partícula que se desloca em MRUV. Assim, são obtidas, a partir do conhecimento prévio das equações horárias para o MRU e para o MRUV, um par de equações paramétricas para as componentes $x(t)$ e $y(t)$ do vetor posição do projétil em duas dimensões. Dessa maneira, as funções horárias para as componentes da posição e da velocidade do projétil serão,

$$
\begin{aligned}
x(t) & =x_{0}+v_{0 x} t \\
y(t) & =y_{0}+v_{0 y} t-\frac{g}{2} t^{2} \\
v_{y}(t) & =v_{0 y}-g t
\end{aligned}
$$

onde $\left\{x_{0}, y_{0}, v_{0 x}, v_{0 y}\right\}$ é um conjunto de condições iniciais e a componente $v_{x}=v_{0 x}$ é constante.

Para encontrar a equação da trajetória, as equações (1) e (2) são combinadas para eliminar o parâmetro temporal, conduzindo a uma relação $y(x)$ entre a altura, $y$, do projétil e a componente horizontal, $x$, de sua posição,

$$
y(x)=y_{0}+\frac{v_{0 y}}{v_{0 x}}\left(x-x_{0}\right)-\frac{g}{2 v_{0 x^{2}}}\left(x-x_{0}\right)^{2} .
$$

Posicionando a origem do referencial no ponto de lançamento e admitindo que o projétil é lançado com velocidade de módulo $v_{0}$ numa direção que forma um ângulo $\theta \operatorname{com}$ a horizontal, o conjunto de valores para as condições iniciais se tornam,

$$
\begin{aligned}
x_{0} & =0, & y_{0} & =0, \\
v_{0 x} & =v_{0} \cos \theta, & v_{0 y} & =v_{0} \operatorname{sen} \theta,
\end{aligned}
$$

de modo que (4) se torna,

$$
y(x)=\operatorname{tg} \theta x-\frac{g \sec ^{2} \theta}{2 v_{0}^{2}} x^{2} .
$$

A equação (7) evidencia o comportamento parabólico da altura em relação ao deslocamento horizontal, além da dependência dos parâmetros da parábola com o ângulo de lançamento $\theta$. A Figura 1 apresenta a trajetória para três lançamentos, todos com velocidades 
de mesmo módulo, $v_{0}$, mas diferentes ângulos de lançamento, $30^{\circ}, 45^{\circ}$ e $60^{\circ}$. Observe que os projéteis lançados com ângulos complementares, no caso, $30^{\circ}$ e $60^{\circ}$ possuem o mesmo alcance, ou seja, caem no mesmo lugar, embora tenham atingido alturas diferentes.

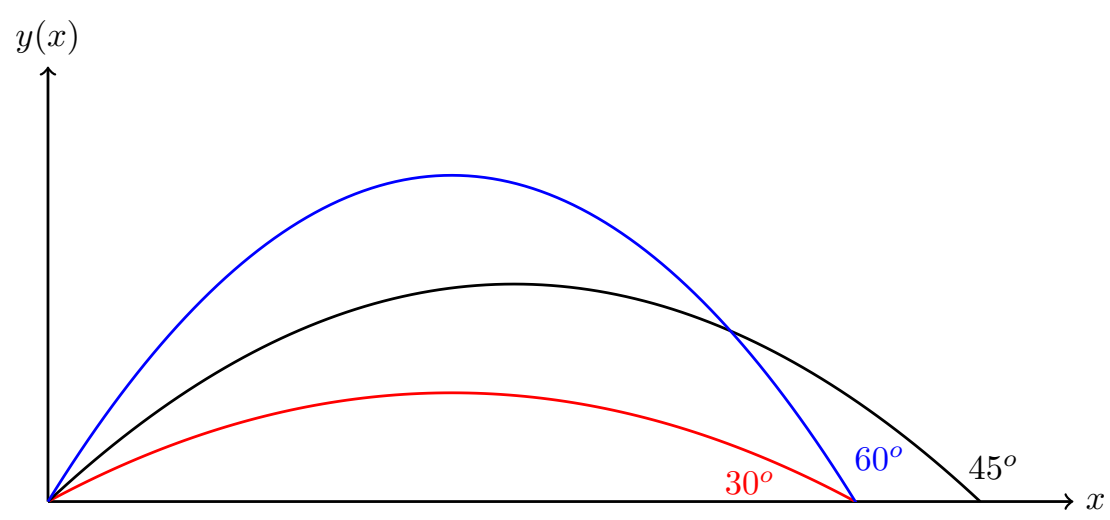

Figura 1: Trajetórias de três projéteis lançados com velocidades iniciais de mesmo módulo vo, em três diferentes ângulos, $30^{\circ}$ (vermelho), $45^{\circ}$ (preto), $60^{\circ}$ (azul).

O alcance de um projétil é definido como a distância horizontal, $R$, entre o ponto de lançamento e o ponto em que o projétil atinge o solo. No modelo, o solo é representado por $y=0$, portanto, fazendo $x=R$ e $y(R)=0$ em (7) obtemos o alcance,

$$
R=\frac{2 v_{0}^{2} \operatorname{sen} \theta \cos \theta}{g}=\frac{v_{0}^{2} \operatorname{sen}(2 \theta)}{g},
$$

que depende do módulo e da direção da velocidade de lançamento, além da intensidade do campo gravitacional.

A Figura 2 apresenta o comportamento do alcance, $R$, em termos do ângulo de lançamento, $\theta$, descrito na equação (8) para projeteis lançados com velocidades de mesmo módulo e sujeitos ao mesmo campo gravitacional. Note que $\theta \in\left[0,90^{\circ}\right]$, onde $\theta=0$ corresponde a um lançamento horizontal e $\theta=90^{\circ}$ corresponde a um lançamento vertical. Em ambos os casos o alcance será $R=0$, no primeiro caso porque o projétil nunca deixa o solo, no segundo porque ele viaja na vertical, retornando para o ponto de partida. É observado, também, que ângulos simétricos em torno de $\theta=45^{\circ}$, ou seja, ângulos complementares, possuem o mesmo alcance, tais como $30^{\circ}$ e $60^{\circ}$ destacados na figura, este é um fato curioso e pouco intuitivo, mas que consegue ser bem absorvido por estudantes, como será discutido na seção IV. Também é evidente na Figura 2 que o alcance de um projétil é máximo quando o ângulo de lançamento é $\theta=45^{\circ}$. De fato, fazendo $\theta=45^{\circ}$ na equação $(8)$, teremos $\operatorname{sen}\left(90^{\circ}\right)=1, \mathrm{o}$ valor máximo de seno, portanto,

$$
R_{\max }=\frac{v_{0}^{2}}{g} .
$$

Embora o alcance de projeteis lançados em ângulos complementares seja o mesmo, as alturas máximas atingidas não o são, como observado na Figura 1, onde é notável que a altura máxima atingida pelo projétil lançado a um ângulo de $60^{\circ}$ é maior que a do projétil lançado a um ângulo de $30^{\circ}$. Para obter as coordenadas correspondentes à altura máxima 


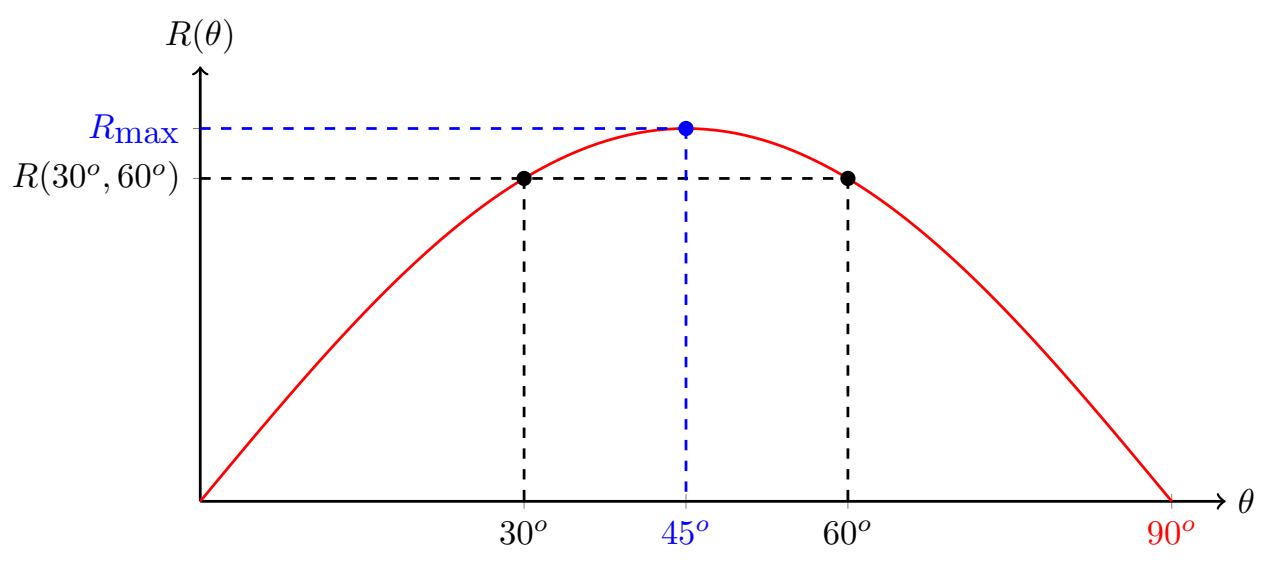

Figura 2: Alcance dos projéteis em função do ângulo de lançamento, quando lançados com velocidades de mesmo módulo.

precisamos combinar as equações (1) e (3) para eliminar o tempo, obtendo,

$$
v_{y}(x)=v_{0} \operatorname{sen} \theta-\frac{g}{v_{0} \cos \theta} x,
$$

a altura máxima ocorre onde a componente vertical da velocidade se anula, $v_{y}\left(x_{\max }\right)=0$, assim, a coordenada $x_{\max }$ do ponto de máxima altura será,

$$
x_{\max }=\frac{v_{0}^{2}}{2 g} \operatorname{sen}(2 \theta),
$$

enquanto a altura máxima atingida pelo projétil será $h_{\max }=y\left(x_{\max }\right)$, que se obtém substituindo (9) em (7). Assim, teremos,

$$
h_{\max }=\frac{v_{0}^{2}}{2 g} \operatorname{sen}^{2} \theta
$$

A Figura 3 apresenta o comportamento das coordenadas do ponto correspondente à altura máxima, a componente $x_{\max }$ na Figura $3 \mathrm{a}$ e $h_{\max }$ na Figura $3 \mathrm{~b}$, em termos do ângulo de lançamento, $\theta$, para projeteis lançados com velocidade de mesmo módulo. A altura máxima cresce monotonicamente com o ângulo de lançamento, atingindo seu valor máximo em $\theta=90^{\circ}$, ou seja, quando a partícula é lançada verticalmente para cima. Já a coordenada $x_{\max }$ aumenta até ser atingido o ângulo de $45^{\circ}$, que também corresponde ao ângulo do alcance máximo, diminuindo até se anular quando o lançamento é vertical.

Verificado o modelo parabólico, é necessário fazer corresponder os cálculos teóricos com a realização física do movimento, ou seja, é preciso que o estudante compreenda que o conjunto de parábolas definidas pela equação (7) e exemplificadas na Figura 1 representem o movimento de uma partícula de qualquer massa lançada com uma velocidade inicial sujeita apenas à ação da gravidade. É especialmente notável, e contra-intuitivo, o fato de que o movimento do projétil não dependa de sua massa, muito menos de sua forma, fatos causados pelas simplificações utilizadas. A independência da forma se deve à consideração do projétil como uma partícula, sem dimensões, portanto não estando sujeito à torques. A 


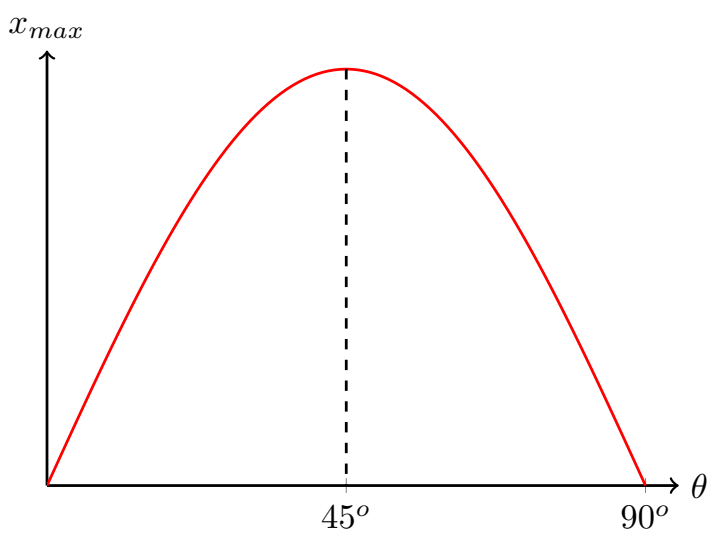

(a)

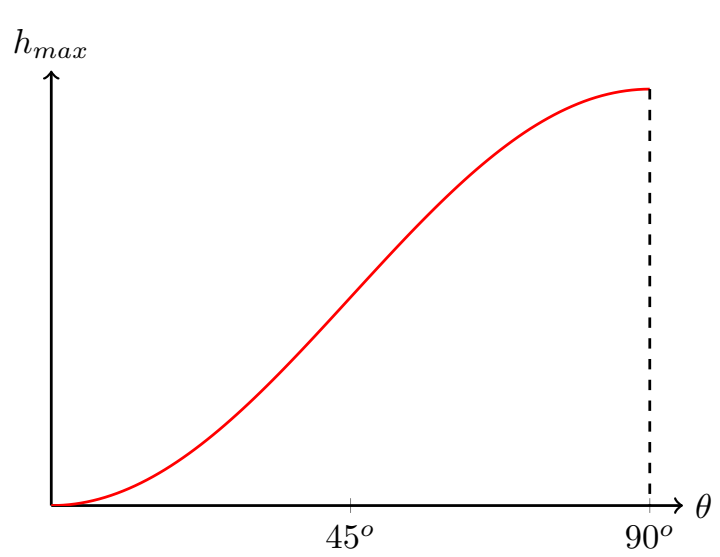

(b)

Figura 3: Coordenadas correspondentes à altura máxima em função do ângulo de lançamento. (a) Coordenada horizontal da altura máxima. (b) Altura máxima.

independência da massa se deve ao fato da única força atuando sobre o projétil ser a força da gravidade, portanto, sendo as massas inercial e gravitacional, consideradas iguais, elas são eliminadas na segunda lei de Newton. Esse cenário não permanecerá se for introduzida a força de resistência viscosa do ar, como veremos a seguir.

\section{II.2. Modelo com Resistência do Ar}

O movimento de um corpo, ou mesmo de uma partícula, através de um fluido, tal como o ar, certamente estará sujeito a uma força resistiva. Tratando o ar como um fluido contínuo, o móvel precisa atravessar o ar, deslocando-o, à medida que se movimenta, é natural, portanto, identificar que o ar exerce uma força no móvel que se opõe ao seu movimento. Além disso, quanto maior for a velocidade do móvel, maior deve ser a força de oposição do ar, pois mais ar precisará ser deslocado por unidade de tempo. Newton estudou o movimento de uma partícula sujeita a forças de resistência do ar que eram proporcionais ao módulo da velocidade ou proporcionais ao quadrado do módulo da velocidade da partícula [Newton 2008]. J. Bernoulli expandiu os estudos de Newton para forças proporcionais a qualquer potência do módulo da velocidade, contudo, os termos lei de resistência de Stokes e lei de resistência de Newton podem ser encontrados para especificar forças de resistência do ar proporcionais ao módulo da velocidade e ao quadrado do módulo da velocidade, respectivamente [Thormton e Marion 2011].

Há várias forças atuando em um projétil ao longo de sua trajetória, que dependem da densidade do ar, da forma e da rugosidade do projétil, se o projetil gira ou vibra, etc. Duas componentes dessas forças são particularmente interessantes, a força de arrasto, ou simplesmente força de resistência, que é oposta à velocidade do projétil; e a força de sustentação, perpendicular à força de arrasto, normalmente responsável pela sustentação do vôo de aeronaves. Entretanto, para este trabalho, tomaremos o caso mais simples, o de uma partícula sujeita a uma força de arrasto proporcional ao módulo da velocidade, ou seja,

$$
\vec{f}_{a}=-b \vec{v}
$$


onde $b$ é um coeficiente positivo, com unidades $\mathrm{kg} / \mathrm{s}$, que depende apenas das características da interação da partícula com o ar, que consideramos isotrópica.

Utilizando o formalismo newtoniano, um projétil lançado sob a ação da gravidade e da força de arrasto (11) será regido pela seguinte equação do movimento,

$$
m \vec{a}=m \vec{g}-b \vec{v}
$$

utilizando a notação padrão,

$$
m \ddot{\vec{r}}+b \dot{\vec{r}}=m \vec{g}
$$

onde $\vec{r}$ é o vetor posição do projétil e cada ponto representa uma derivação temporal total. Considerando o movimento em duas dimensões, sendo o eixo $x$ horizontal e o eixo $y$ vertical e orientado para cima, teremos,

$$
\begin{aligned}
& m \ddot{x}+b \dot{x}=0 ; \\
& m \ddot{y}+b \dot{y}=-m g .
\end{aligned}
$$

Definindo $\gamma \equiv b / m$, encontramos,

$$
\begin{aligned}
& \ddot{x}+\gamma \dot{x}=0 \\
& \ddot{y}+\gamma \dot{y}=-g,
\end{aligned}
$$

As expressões (13) e (14) são as equações do movimento do projétil pontual de massa $m$. Observem que a massa não foi eliminada, ela está embutida no parâmetro $\gamma$, com unidades de $s^{-1}$; o caso $\gamma=0$ se reduz ao caso sem resistência do ar, equações (1) e (2). Como $\gamma$ é inversamente proporcional à massa e as dimensões do projétil estão sendo desprezadas, espera-se que um projétil de maior massa sofra menos os efeitos da resistência do ar.

Considerando que o projétil é lançado com as condições iniciais (5) e (6), as equações (13) e (14) podem ser resolvidas, levando a,

$$
\begin{aligned}
& x(t)=v_{0} \cos \theta\left(\frac{1-e^{-\gamma t}}{\gamma}\right), \\
& y(t)=-\frac{g t}{\gamma}+\left(\gamma v_{0} \operatorname{sen} \theta+g\right)\left(\frac{1-e^{-\gamma t}}{\gamma^{2}}\right) .
\end{aligned}
$$

O limite $\gamma \rightarrow 0$ não é evidente nas equações (15) e (16), entretanto, as equações (1) e (2) são reproduzidas (apêndice A) quando a força de arrasto se torna desprezível, como esperado fisicamente.

Encontrar a equação da trajetória eliminando t entre as equações (15) e (16) não é simples, portanto, continuaremos utilizando as equações paramétricas para estudar o movimento. A Figura 4 apresenta a trajetória de três projeteis idênticos, com mesma massa, lançados com velocidades de mesmo módulo, mas com diferentes ângulos de lançamento, $\theta=30^{\circ}, 45^{\circ}, 60^{\circ}$, diferentemente do que acontece no caso sem resistência do ar, o alcance máximo não ocorre necessariamente no ângulo de $45^{\circ}$, nem tão pouco os lançamentos em ângulos complementares têm o mesmo alcance (compare com a Figura 1). 


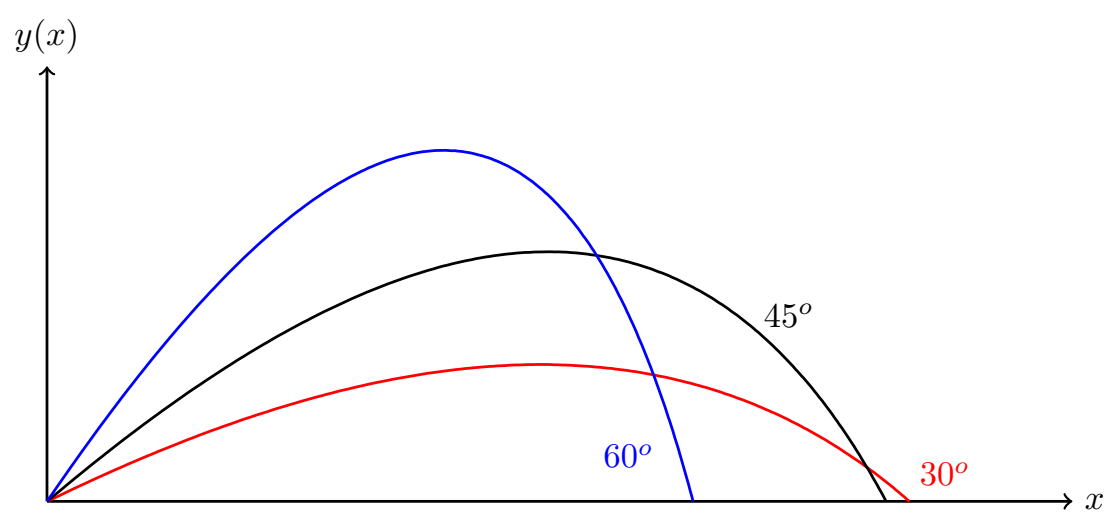

Figura 4: Trajetórias de três projéteis idênticos lançados com velocidades iniciais de mesmo módulo, em três diferentes ângulos, $30^{\circ}$ (vermelho), $45^{\circ}$ (preto), $60^{\circ}$ (azul) e sujeitos à força de arrasto linear.

O efeito da resistência do ar pode ser observado na Figura 5, onde são apresentadas as trajetórias de projeteis lançados com a mesma velocidade, em módulo e direção, mas sujeitos a forças de arrasto de diferentes intensidades. A curva tracejada representa o limite $\gamma \rightarrow 0$. A redução do efeito da resistência do ar pode ser interpretada de duas maneiras: como um mesmo projétil sendo lançado em uma região onde se faz vácuo cada vez mais alto, tornando o ar mais e mais rarefeito, ou projéteis de massas cada vez maiores, tornando o efeito da resistência do ar desprezível em comparação com a força da gravidade.

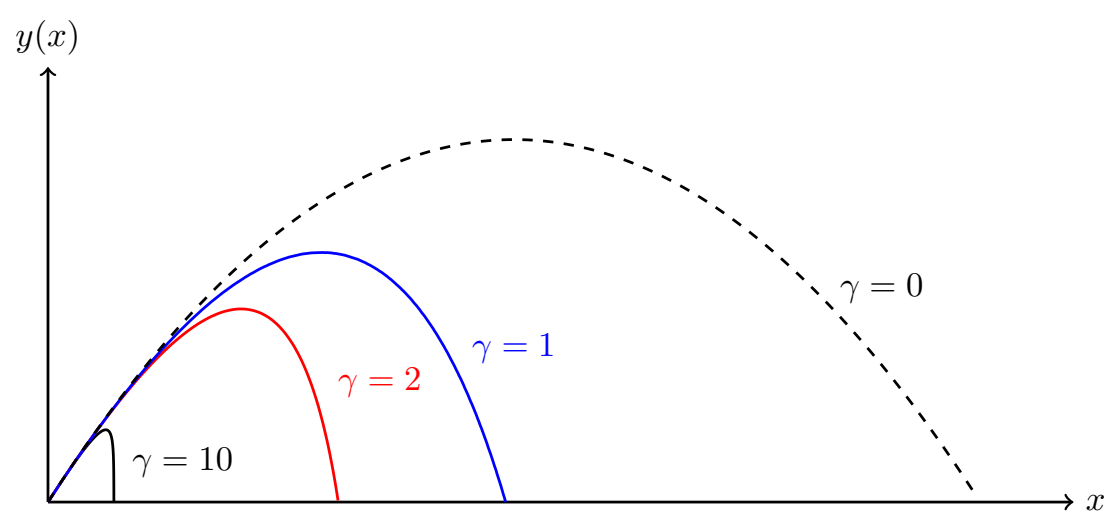

Figura 5: Trajetórias de projéteis lançados com velocidades iniciais idênticas, em módulo e direção, mas sujeitos a diferentes forças de resistência linear.

Para descobrir o alcance dos projéteis através das equações (15) e (16), precisaremos definir o tempo de vôo, $T$, ou seja, o intervalo de tempo entre o lançamento e a aterrissagem do projétil. Assim, fazendo $y(T)=0$ na equação (16) encontramos que o tempo de vôo deve satisfazer,

$$
\gamma T=\left(\frac{\gamma v_{0} \operatorname{sen} \theta}{g}+1\right)\left(1-e^{-\gamma T}\right) .
$$

Observe que $T=0$ é uma solução trivial da equação (17), significando o instante de lançamento, portanto, o tempo de vôo será representado pela solução não-trivial, $T>0$. 
Definindo,

$$
\begin{aligned}
& \tau \equiv \gamma T \\
& A \equiv \frac{\gamma v_{0} \operatorname{sen} \theta}{g}+1
\end{aligned}
$$

a equação para o tempo de vôo se reduz a,

$$
\tau=A\left(1-e^{-\tau}\right)
$$

A equação (20) é uma equação transcendental, contudo, ela pode ser resolvida exatamente em termos da função W de Lambert [Corless et al. 1996] (apêndice B), portanto,

$$
\tau=A+W\left(-A e^{-A}\right)
$$

Utilizando (20) em (15) e então (21) é obtido o alcance do projétil,

$$
R=v_{0} \cos \theta\left(\frac{\tau}{\gamma A}\right)=\frac{v_{0} \cos \theta}{\gamma}\left[1+\frac{W\left(-A e^{-A}\right)}{A}\right]
$$

onde $A$ está especificado em (19) e $\tau$ é fornecido por (21). O alcance $R$, portanto, depende de forma não-trivial dos parâmetros do modelo, ou seja, do módulo da velocidade inicial, da intensidade do campo gravitacional, do coeficiente de resistência do ar, da massa do projétil e do ângulo de lançamento.

A Figura 6 ilustra o comportamento do alcance de um projétil em função do ângulo de lançamento para um coeficiente de arrasto fixo. É notável uma assimetria em torno do alcance máximo, que, neste caso, ocorre em algum ângulo no intervalo $\left(30^{\circ}, 40^{\circ}\right)$, diferentemente do caso sem resistência do ar.

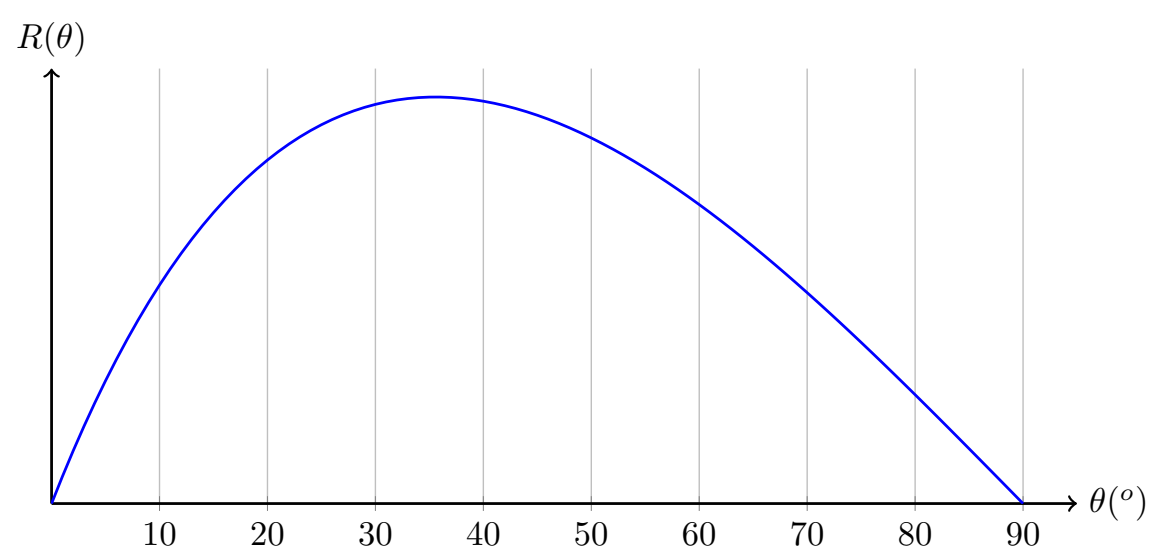

Figura 6: Alcance do projétil sujeito à força de arrasto linear em função do ângulo de lançamento.

A Figura 7 apresenta o comportamento do alcance dos projéteis lançados com velocidades de mesmo módulo e mesma direção, mas sujeitos a diferentes forças de arrasto, correspondentes às trajetórias apresentadas na Figura 5. É observado, como se espera, que o alcance para qualquer ângulo (exceto $\theta=0,90^{\circ}$ ) aumenta com a redução da força de arrasto. 
Entretanto, é curioso que aumentando a força de arrasto, o alcance máximo ocorra em ângulos menores, deixando a curva mais assimétrica em relação ao máximo, evidenciando a não correspondência dos alcances de projéteis lançados com ângulos complementares, como acontece quando não há resistência do ar.

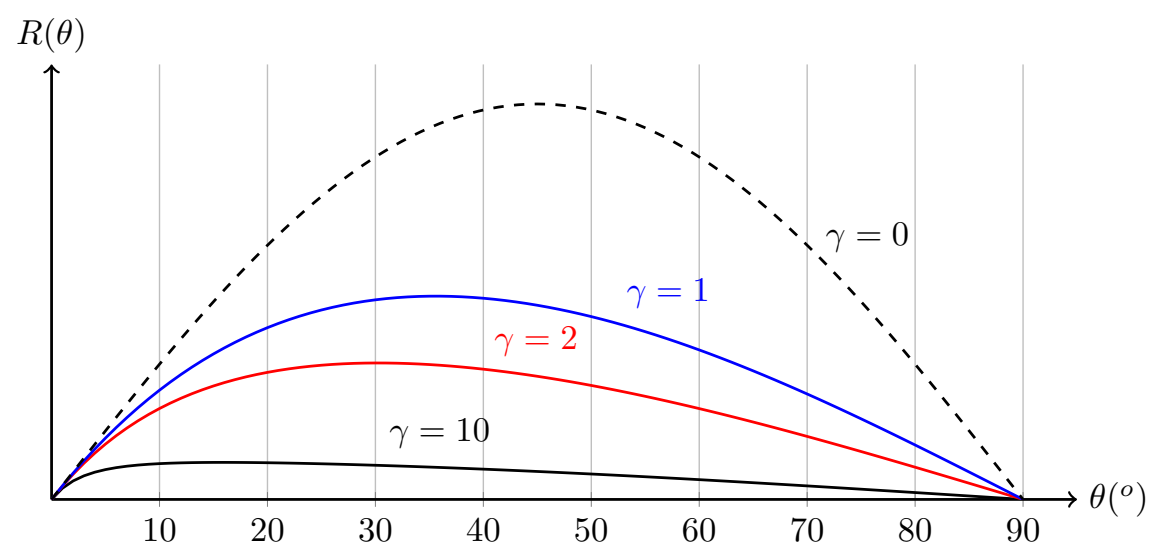

Figura 7: Alcance de projéteis sujeitos à diferentes forças de arrasto linear em função do ângulo de lançamento.

Os valores dos ângulos correspondentes ao alcance máximo, podem ser obtidos exatamente, a partir da expressão (22), o cálculo é extenso, levando a uma nova equação transcendental envolvendo funções trigonométricas e a função $W$ de Lambert. Essa equação pode ser resolvida numericamente, utilizando o software livre Maxima [Santos e Rocha 2009, Sistema de álgebra computacional Maxima 2019]. A Figura 8 apresenta o comportamento do alcance máximo, $R_{\max },(8 \mathrm{~b})$ e de seu ângulo correspondente, $\theta_{\max }(8 \mathrm{a}) \mathrm{em}$ termos do coeficiente de arrasto. Como esperado, quando o coeficiente de arrasto se torna desprezível $\theta_{\text {max }} \rightarrow 45^{\circ}$, decrescendo acentuadamente à medida que a resistência do ar aumenta. O mesmo acontecendo para o alcance máximo (8b), novamente, o maior alcance acontece quando a resistência do ar é desprezível, diminuindo acentuadamente à medida que a força de resistência do ar se torna mais relevante.

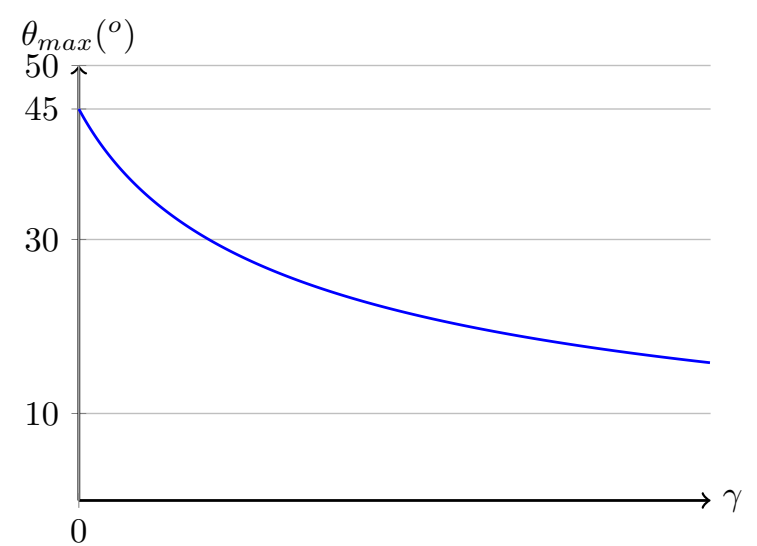

(a)

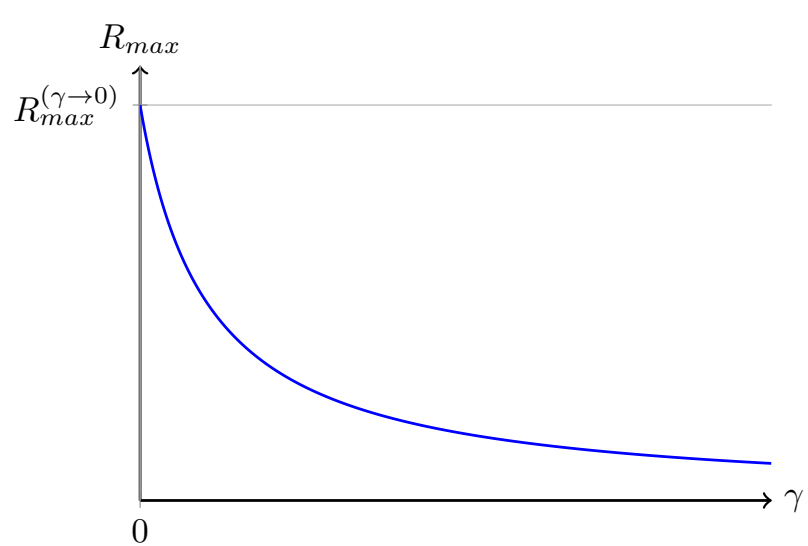

(b)

Figura 8: Alcance máximo de um projétil sujeito à força de arrasto linear. (a) Ângulo do alcance máximo. (b) Alcance máximo. 
Dessa maneira, observamos que a introdução de uma força de resistência viscosa linear já é suficiente para modificar qualitativamente o comportamento de um projétil em relação ao lançamento sem resistência do ar. Entretanto, o resultado sem resistência do ar pode ser utilizado com precisão razoável no caso em que o força de resistência se torna desprezível, por exemplo, lançando-se projéteis geometricamente idênticos, porém de massas maiores e portanto uma relação entre a força de resistência e o peso menores, além de densidades grandes quando comparadas com a densidade do fluido que compõem o meio - desde que a forma dos projéteis não introduzam novos componentes, como rotação, ou outros graus de liberdade. Como veremos na seção III, o modelo de lançamento oblíquo com resistência do ar proporcional à velocidade, mesmo simples, será mais do que suficiente para se modelar com eficácia as atividades experimentais propostas neste trabalho, sobretudo quando embebidas em atividades de caráter investigativo.

\section{Metodologia Experimental}

De modo análogo à seção anterior, nesta seção descreveremos os pormenores realizados durante as atividades experimentais propostas [Melo 2019]. Conforme dito anteriormente, os experimentos foram realizados com brinquedos e uma plataforma de lançamento artesanal, produzido através de materiais de baixo custo, fácil montagem e utilização. O protótipo possui um suporte de madeira, apresentado na Figura 9, composto por uma plataforma de lançamento ajustável, a qual pode ser fixada por prego, alfinete, clipe de papel, etc, em uma escala angular.

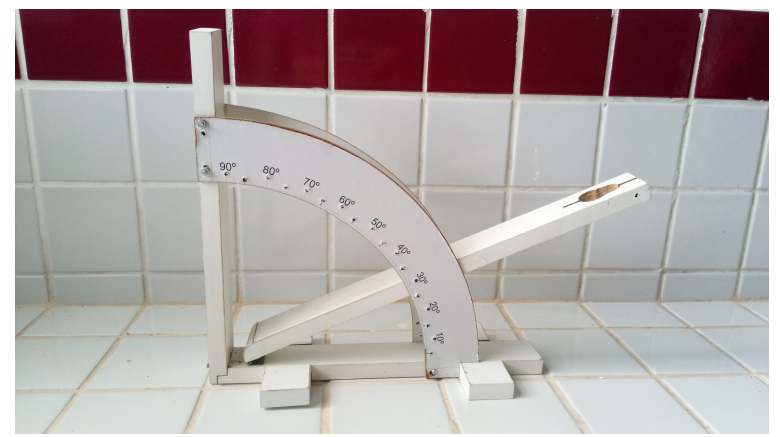

(a)

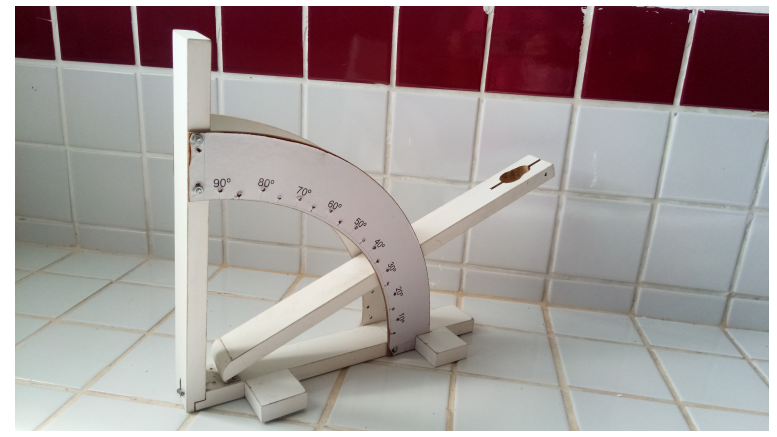

(b)

Figura 9: Suporte de madeira com escala angular e plataforma ajustável. (a) Fotografia de perfil do suporte de madeira. (b) Fotografia lateral do suporte de madeira.

O lançamento é realizado com pistolas de mola de brinquedo, uma delas é apresentada na Figura 10a, acopladas à plataforma de madeira. Os projéteis, uma bolinha de plástico, um dardo de borracha e um dardo com ventosa, cujas massas medidas com uma balança de precisão estão especificadas na Tabela 1, são apresentados na Figura 10b. Cada projétil é lançado por uma pistola apropriada, na Figura 10a é apresentada a pistola para o dardo com ventosa. Além do suporte e do lançador, são necessários uma trena, para medirmos o alcance dos projeteis, e um cronômetro para medir o tempo de vôo dos projéteis; o cronômetro pode 
Tabela 1: Massas dos projéteis de brinquedo.

\begin{tabular}{lc}
\hline Projétil & Massa $(\mathrm{g})$ \\
\hline Bolinha & 0,6606 \\
\hline Dardo de Borracha & 1,1870 \\
\hline Dardo com Ventosa & 1,1939 \\
\hline
\end{tabular}

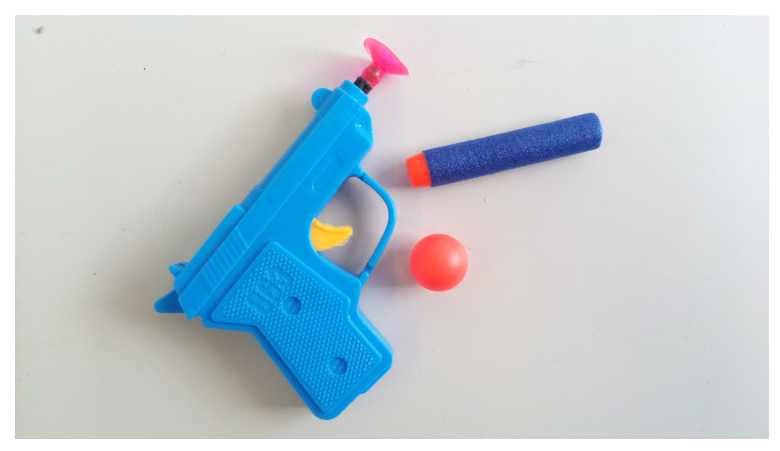

(a)

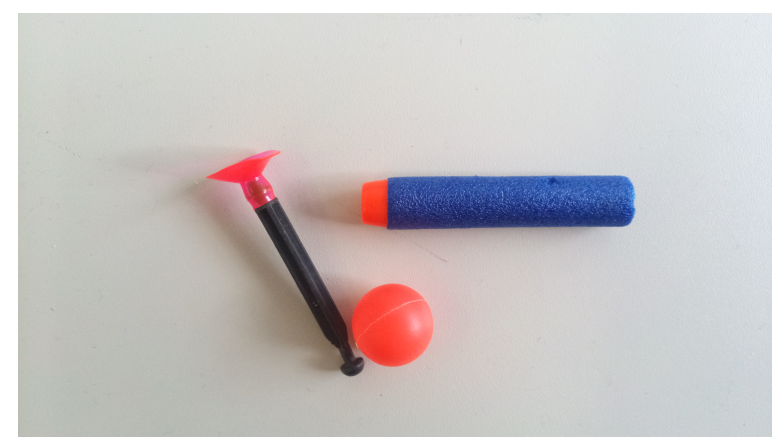

(b)

Figura 10: Lançador de brinquedo e projéteis utilizados no experimento. (a) Fotografia de uma das pistolas de brinquedo utilizadas como lançador. (b) Fotografia dos projéteis lançados com as pistolas de brinquedo.

ser encontrado em aparelhos de telefone celular do tipo smartphones, hoje de uso comum entre docentes e estudantes.

Os experimentos foram realizados em ambiente fechado, para evitar correntes de ar e suficientemente amplo para permitir o vôo completo dos projéteis. Além disso, a plataforma e os lançadores eram cuidadosamente reposicionados a cada lançamento, para permitir que as condições iniciais fossem sempre similares.

Mesmo sendo tomados os cuidados necessários, ainda há incertezas produzidas por imprecisões aleatórias, por exemplo, há uma imprecisão na medida do tempo de vôo, devido ao tempo de reação do experimentador tanto ao acionar o cronômetro no instante do lançamento quanto ao paralisá-lo no instante da aterrissagem. A distensão da mola no interior da pistola também não é conhecida com precisão, podendo ser diferente a cada lançamento. Além disso, o ponto de queda do projétil observado a olho, também é medido com imprecisão. Para reduzir os efeitos dos erros aleatórios, são realizados vinte lançamentos idênticos, para se produzir valores médios dessas grandezas, juntamente com seus respectivos desvios padrões.

Cada projétil é lançado em diferentes ângulos, variando de $20^{\circ}$ até $60^{\circ}$ em intervalos de $5^{\circ}$, sendo medidos o tempo de vôo e o alcance do projétil. Cada medida é repetida 10 vezes para obter valores médios, reduzindo os erros aleatórios discutidos acima. As medidas para ângulos inferiores a $20^{\circ}$ e superiores a $60^{\circ}$ apresentaram dificuldades de medição, por isso foram descartas neste trabalho.

A Figura 11 apresenta o alcance médio do projétil em forma de "bolinha" (fig. 10b) com os respectivos desvios padrões. As curvas contínuas representam o comportamento teórico do alcance de um projétil pontual, a curva azul apresenta um ajuste empírico (por olho) 


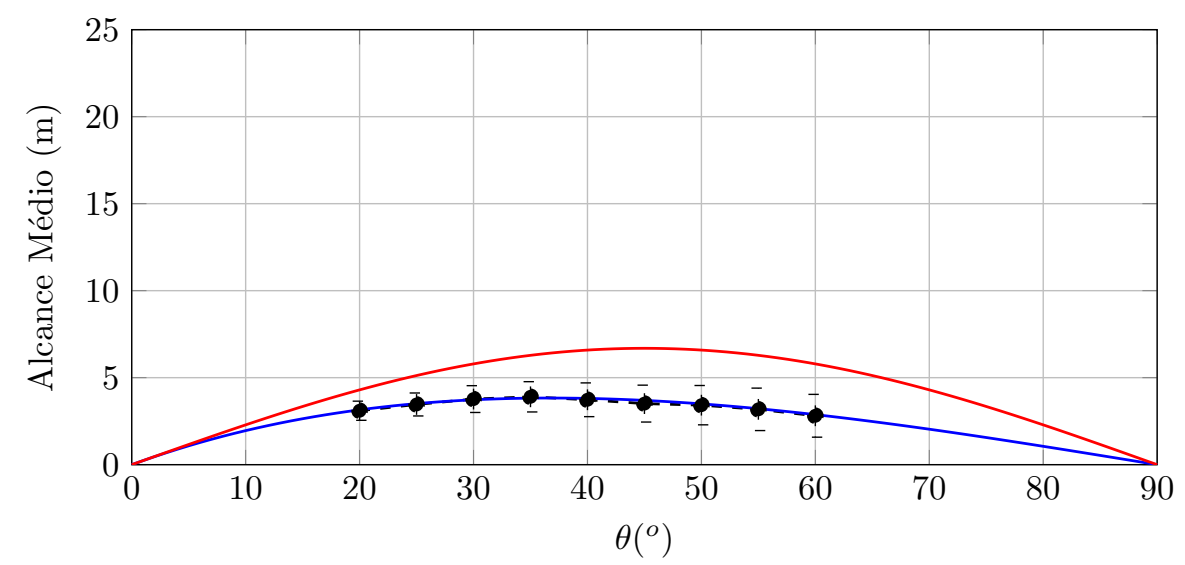

Figura 11: Alcance médio de projéteis "bolinha" lançados com diferentes ângulos de lançamento. Pontos representam as medidas experimentais, a curva azul o esperado pelo modelo com resistência do ar e a curva vermelha o esperado pelo modelo sem resistência do ar. Os parâmetros usados para ajustar os modelos foram: $v_{0}=8,2 \mathrm{~m} / \mathrm{s}, g=9,81 \mathrm{~m} / \mathrm{s}^{2}$ e $\gamma=1,0 \mathrm{~s}^{-1}$.

feito para o modelo com resistência do ar, os parâmetros do ajuste foram: $v_{0}=8,2 \mathrm{~m} / \mathrm{s}$, $g=9,81 \mathrm{~m} / \mathrm{s}^{2}$ e $\gamma=1,0 \mathrm{~s}^{-1}$. A curva vermelha apresenta o comportamento esperado pelo modelo sem resistência do ar, utilizando os mesmos parâmetros. É observado que um projétil esférico é bem representado por uma partícula, desde que o projétil não seja lançado com algum momento angular, o que poderia potencializar forças de sustentação, mas o efeito da resistência do ar condiz com o modelo linear. $O$ modelo sem resistência não reproduz um bom ajuste, mesmo dentro das barras de erro do experimento.

A Figura 12, por sua vez, apresenta o alcance médio dos projéteis assimétricos, o "dardo de borracha" (fig. 12a) e o "dardo com ventosa" (fig 12b). Nestes casos não é possível um ajuste completo dos dados por nenhum dos modelos teóricos para o lançamento de uma partícula, seria necessário acrescentar, portanto, as dimensões dos projéteis. Contudo, ainda é possível aproximar algumas regiões com o modelo com resistência do ar, como é o caso do lançamento do "dardo de borracha" para grandes ângulos observado na Figura 12a. O ajuste do modelo com resistência do ar foi realizado com os seguintes parâmetros: $v_{0}=15,0 \mathrm{~m} / \mathrm{s}$, $g=9,81 \mathrm{~m} / \mathrm{s}^{2}$ e $\gamma=2,0 \mathrm{~s}^{-1}$. O comportamento do "dardo com ventosa", espantosamente, apresentou uma boa concordância com o modelo teórico para a partícula com resistência do ar dentro da barra de erro, embora o comportamento médio não aparente acompanhar a mesma curvatura, neste caso o ajuste foi realizado com os parâmetros: $v_{0}=13,0 \mathrm{~m} / \mathrm{s}$, $g=9,81 \mathrm{~m} / \mathrm{s}^{2}$ e $\gamma=2,0 \mathrm{~s}^{-1}$. Em ambos os casos, o modelo sem resistência do ar com os mesmos parâmetros apresenta uma grande discrepância. As três figuras estão na mesma escala para facilitar a comparação.

Vemos então que de posse de dois modelos teóricos e de atividades experimentais que permitam a validação de apenas um deles, tem-se em mãos ferramentas necessárias, mas não suficientes para potencializar mudanças conceituais. Tal mudança, não versa apenas o conteúdo específico (efeito da resistência do ar), mas também a postura epistemológica frente ao grau de realismo dos modelos teóricos. Assim, acreditamos que além propor modelos teóricos, protocolos experimentais e instrumentação, formular situações problematizadoras com tais ferramentas, constitui etapa imprescindível ao processo de construção 


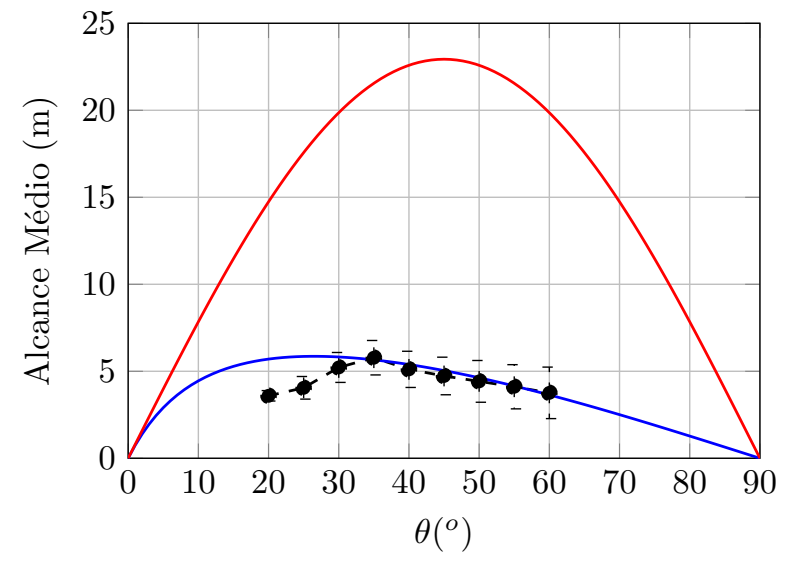

(a)

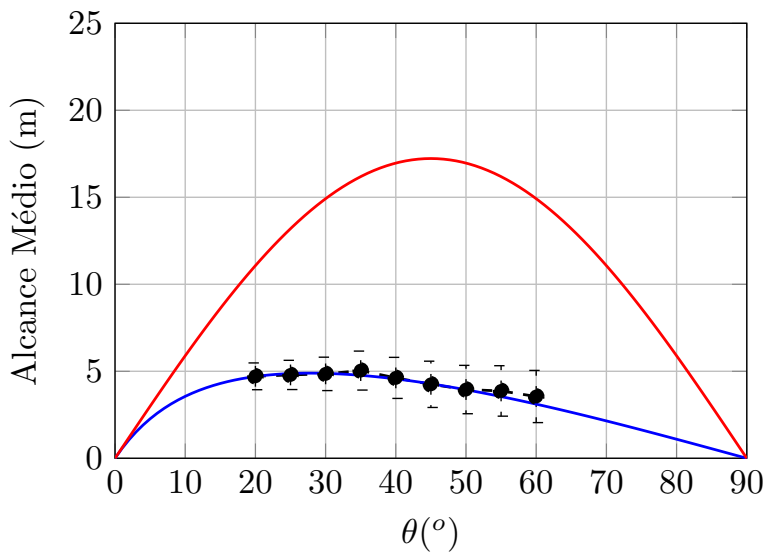

(b)

Figura 12: Alcance médio dos projéteis assimétricos: "Dardo de Borracha" e "Dardo com Ventosa". Pontos representam as medidas experimentais, a curva azul o esperado pelo modelo com resistência do ar e a curva vermelha o esperado pelo modelo sem resistência do ar. (a) Alcance médio de projéteis "Dardo de Borracha" lançados com diferentes ângulos de lançamento. Ajuste dos modelos com os parâmetros: $v_{0}=15,0 \mathrm{~m} / \mathrm{s}, g=9,81 \mathrm{~m} / \mathrm{s}^{2}$ e $\gamma=2,0 \mathrm{~s}^{-1}$. (b) Alcance médio de projéteis "Dardo com Ventosa" lançados com diferentes ângulos de lançamento. Ajuste dos modelos com os parâmetros: $v_{0}=13,0 \mathrm{~m} / \mathrm{s}, g=9,81 \mathrm{~m} / \mathrm{s}^{2}$ e $\gamma=2,0 \mathrm{~s}^{-1}$.

do conhecimento. Tendo isso em mente, na próxima seção faremos uma breve abordagem sobre ensino por investigação e, com base nessa metodologia, iremos sugerir situações nas quais as 'ferramentas' discutidas nas seções anteriores possam ser inseridas com eficácia.

\section{LANÇAMENTO ObLIQUO COM RESISTÊNCIA DO AR: UMA PROPOSTA DE ENSINO POR INVESTIGAÇÃO}

\section{IV.1. Breve digressão sobre ensino por investigação}

O termo problema aparece frequentemente em livros didáticos. No entanto, como assinala Carvalho [Carvalho 2014] tal termo é costumeiramente colocado de maneira equivocada: o que é chamado de problema, na maioria das vezes, relaciona-se com a resolução de exercícios que, em grande parte, além de não possuirem contextualização com o mundo real, tanto as etapas para a sua solução bem como o resultado final a que se deve chegar, já estão dados. Com isso vemos que nesse processo - resolução com etapas pré-definidas - o estudante não possui grau de liberdade, fato este que reduz o procedimento a um protocolo mnemônico, muitas vezes desprovido de senso crítico.

Processo diferente ocorre no âmbito do ensino por investigação. Neste caso o estudante depara-se com situações desconhecidas, ante as quais, aquele que resolve se sente inicialmente perdido. Tais situações devem conter características de um trabalho científico, tais como: resolução de problemas com teoria e prática (experimentais) correlacionadas, formulação de hipóteses, testes dessas hipóteses (com experimentos ou "lápis e papel"), obtenção e análise dos resultados, confrontando-os com as hipóteses. Dito de outra forma, 
além do trabalho de manipulação e/ou observação, o aluno no âmbito de uma proposta investigativa, deve ter um espírito científico. Dentre as principais técnicas envolvendo ensino por investigação temos: questões abertas, problemas abertos, demonstrações investigativas e laboratórios abertos; que descreveremos de forma sucinta a seguir.

Questões abertas: esta atividade investigativa consiste no estudo de algum fenômeno relacionado com o dia a dia do aluno cuja explicação pode estar relacionada com conceitos já estudados e construídos em sala de aula ou com conceitos ainda não estudados. Neste último caso uma questão aberta serve para externalizar concepções espontâneas (concepções cientificamente equivocadas) dos estudantes. Contudo, se os conceitos já foram abordados pelo professor, apresentam-se situações nas quais este novo conhecimento possa ser aplicado. Neste sentido essas atividades ajudam os alunos a desenvolverem seu poder argumentativo, organização de suas ideias, reflexões sobre problemas e situações, como deve agir e quais caminhos ele deve seguir constituindo assim em importante ferramenta para se auferir supostas mudanças conceituais.

Demonstrações investigativas: uma demonstração investigativa inicia-se com um problema experimental relacionado ao conteúdo abordado. A partir dele, os estudantes são retirados do estado de inércia "intelectual", ou seja, deixam de ser meros expectadores das aulas (posição de passividade) passando a pensar, agir, interferir, argumentar, interpretar, analisar e levantar hipóteses, além de defender suas explicações perante aos colegas de sala de aula. Assim como nas questões abertas, quando versam sobre um determinado conteúdo e são realizadas antes de se apresentar tal conteúdo, constituem uma poderosa ferramenta para levantamento de concepções espontâneas (ou alternativas) dos estudantes. Se realizadas após a apresentação do conteúdo, são ferramentas para detectar mudanças conceituais.

Problemas abertos: um problema aberto consiste em um estado que se assemelhe ao mundo real, tal que apresente uma situação apenas parcialmente conhecida envolvendo um conteúdo já estudado. Tais problemas estão em seu estado inicial à espera de hipóteses, simplificações, abstrações, devendo, necessariamente, levar à matematização dos resultados - daí a exigência de um conteúdo já visto. Em geral, tais resultados exigem que os alunos façam seus próprios julgamentos e elaborem argumentações para defender suas soluções.

Laboratório (semi) aberto: diferentemente dos guias altamente estruturados tipo "receita de bolo", onde grupos de estudantes apenas seguem o passo a passo proposto pelo guia (laboratório fechado), um laboratório aberto consiste em um problema aberto a ser resolvido experimentalmente, valendo-se também de uma teoria previamente estudada. Assim, além das etapas contidas nos problemas abertos, temos - a depender do grau de liberdade que se dá aos estudantes - as etapas inerentes ao processo de experimentação: confecção do aparato experimental, obtenção de dados/medições, organização dos dados em tabelas e gráficos para posterior comparação com modelo matemático e sua validação ou não. Note que teoria e experimento nesta proposta são 
indissociáveis: o modelo matemático guia a construção do aparato experimental e/ou vice-versa - o experimento sugere um determinado modelo teórico.

Em se tratando de liberdade frente a uma atividade experimental, Carvalho [Carvalho 2018] procurou determinar o grau de liberdade intelectual que professores (P) e alunos (A) possuem diante de uma dada atividade experimental, que colocamos de forma condensada na Tabela 2.

Tabela 2: Graus de liberdade de uma atividade experimental

\begin{tabular}{|l|c|c|c|c|c|}
\hline & Grau I & Grau II & Grau III & Grau IV & Grau V \\
\hline Problema & P & P & P & P & A \\
\hline Hipóteses & P & P & P & A & A \\
\hline Plano de trabalho & P & P & A & A & A \\
\hline Obtenção de dados & A & A & A & A & A \\
\hline Conclusões & P & A & A & A & A \\
\hline
\end{tabular}

Graus de liberdade do professor/aluno em aulas de laboratório

Grosso modo, na Tabela 2 temos:

Grau I - o estudante tem apenas liberdade de obter os dados, ou seja, aulas do tipo "receita de bolo". Essas aulas, infelizmente, são encontradas até hoje e, neste caso, temos um laboratório fechado.

Grau II - o resultado final não é dado de modo que os estudantes têm a liberdade de tirarem suas conclusões a partir da obtenção de seus dados. Nesse tipo de atividade há a necessidade de uma mudança estrutural sobre como são inseridos [discutidos] os problemas [resultados];

Grau III - os estudantes são livres para elaborar seus próprios planos de trabalho, obter seus dados e realizarem suas conclusões.

Grau IV - os estudantes recebem apenas o problema e desenvolvem todo o trabalho intelectual;

Grau V - os estudantes propõem inclusive o problema, além de todas as etapas posteriores (modelo teórico, aparato experimental, etc...) para a sua solução.

Diante do exposto, aplicaremos os experimentos supracitados em caráter de demonstração investigativa após trabalharmos lançamento obliquo sem resistência do ar, com o intuito de levantar concepções espontâneas acerca da validade deste modelo teórico pelos estudantes. De posse deste levantamento, proporemos um laboratório semi-aberto que leve em conta efeitos de resistência do ar valendo-se do modelo desenvolvido na seção II. 


\section{IV.2. Demonstrações investigativas: concepções dos estudantes sobre o modelo sem resistência do ar}

O experimento descrito na seção III foi utilizado como instrumento mediador em aulas aplicadas a uma turma de terceiro ano do ensino médio contendo 37 estudantes, da escola Alexandrino da Rocha, localizada na cidade de Bonito, no estado de Pernambuco. Inicialmente, foi realizada uma aula teórico-conceitual tradicional (sem atividades experimentais) com duração de uma hora e quarenta minutos, sobre os assuntos relevantes ao lançamento de um projétil, revisando o modelo para lançamento sem resistência do ar, descrito na subseção II.1. Foram particularmente abordadas questões relacionadas ao alcance do projétil, sua relação com o ângulo de lançamento, sendo discutido que em determinadas situações (não especificadas), o efeito da resistência do ar era relevante e deveria ser levado em consideração. Ao final, o equipamento experimental - os brinquedos - foi apresentado, mas sem serem utilizados neste momento. Em um segundo momento (segunda aula), os brinquedos foram utilizados - com os estudantes convidados a manipulá-los - e a seguinte questão - antes de realizar demonstrações investigativas com alguns lançamentos para valores de ângulo: $\theta<45^{\circ}, \theta=45^{\circ}$ e $\theta>45^{\circ}$ - foi proposta: Para esses brinquedos, qual o ângulo de lançamento no qual o projétil chegará mais longe (alcance máximo)? O resultado encontra-se no Figura 13.

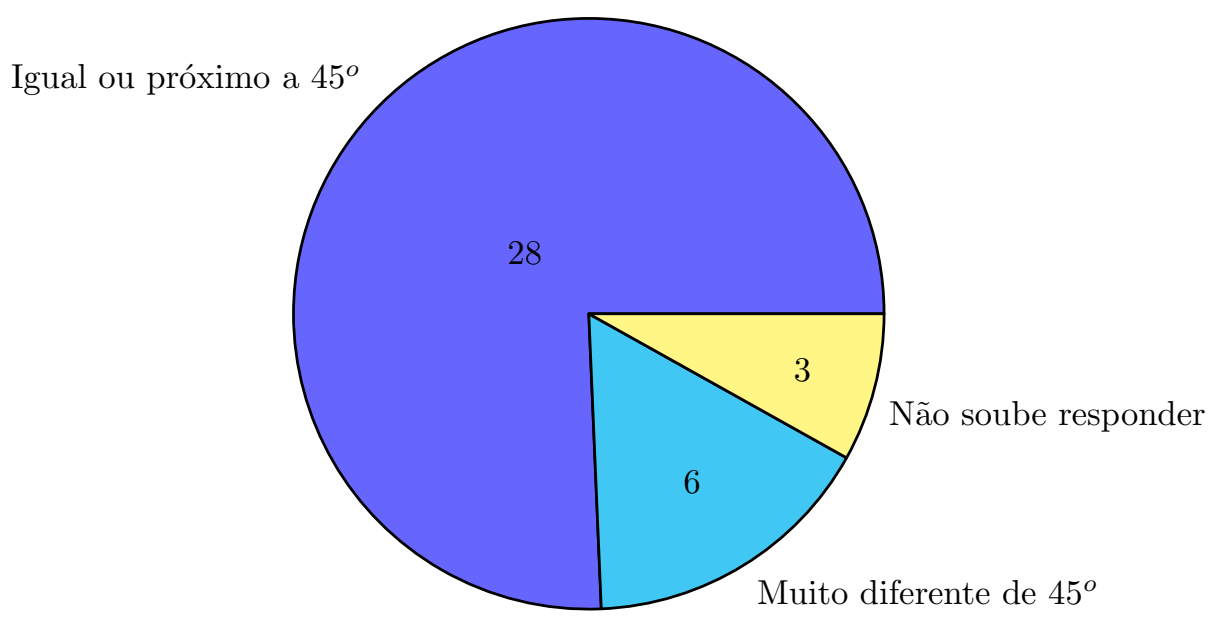

Figura 13: Número de espostas dos estudantes sobre em qual ângulo o projétil chegará mais longe.

Uma análise das respostas a essa questão, mostra que muitas das previsões dos estudantes sobre o lançamento de projéteis estão fortemente vinculadas ao modelo de lançamento oblíquo sem resistência do ar, mesmo deixando explicito no primeiro encontro a limitação do modelo. Fica evidente a existência do realismo ingênuo acerca deste modelo teórico (sem resistência do ar) quando, por exemplo, para muitos estudantes $(75,7 \%)$, mesmo em uma futura situação envolvendo resistência do ar, as conclusões obtidas com o modelo sem resistência do ar não sofreram alteração significativa: o ângulo necessário para obtermos o maior alcance, por exemplo, continuaria sendo o ângulo de $45^{\circ}$ (ou quase $45^{\circ}$ ). Alguns sugerem ainda que com um ângulo acima de $45^{\circ}$ o projétil atingirá uma maior altura, porém não se afastará muito horizontalmente, retornando a uma distância menor do que voltariam com um ângulo menor de lançamento, previsão condizente com o modelo sem resistência 
do ar.

Num terceiro momento - ainda no segundo encontro - demonstrações investigativas com os projéteis lançados diversas vezes, com ângulos de $35^{\circ}, 45^{\circ}$ e $55^{\circ}$ foram realizadas. Para cada projétil, tomando-se a média de cinco lançamentos, é possível chegar a resultados que invalidam o modelo sem resistência do ar. Percebe-se a partir daí, o surgimento de conflitos cognitivos gerados pela discrepância entre o modelo sem resistência do ar (e a postura realista ingênua dos estudantes para com esse modelo) e a demonstração investigativa envolvendo o lançamento de projéteis de brinquedo com ângulos iguais, maiores e menores que $45^{\circ}$. Carvalho ( [Carvalho 2014], p. 48) define conflito cognitivo como uma estratégia:

Segundo o qual o aluno aprende se suas ideias espontâneas sobre determinados fenômenos são colocadas em conflito com as observáveis, ou seja, se suas previsões ou antecipações elaboradas dentro de um esquema conceptual espontâneo são contrariadas por resultados experimentais.

Vemos então que uma vez gerado um conflito cognitivo, tem-se o ambiente pedagógico propício para se propor uma atividade experimental investigativa (mais especificamente um laboratório aberto) fato que faremos na próxima seção.

\section{IV.3. Sugestão de laboratório (semi) aberto com base nas concepções dos estudantes}

Segundo Bachelard [Bachelard 2002] 'Todo novo conhecimento é resposta a uma pergunta'. Assim, uma vez 'plantada a dúvida' acerca da validade ou não do modelo teórico sem resistência do ar, pode-se propor uma atividade experimental aberta de grau II, conforme mostra a tabela 2. O grau II foi escolhido pelo fato que: por termos apenas um aparato experimental para que a aquisição de dados pudesse ser feita em uma aula regular, tal coleta necessariamente teve que ser feita de forma coletiva. Dito de outra forma, todas as etapas do experimento foram realizadas pela turma como um todo, em uma sala de aula 'padrão' e, portanto, sem a necessidade de um laboratório específico de Física. Salientamos que, apesar de haver tempo suficiente para a coleta de dados, sugerimos que uma aquisição prévia dos mesmos seja feita e tratada (média e desvio padrão) pelo docente, em casa, antes da aula.

Assim, de posse dos dados e das expressões finais do alcance do projétil - com e sem resistência do ar - ambos os modelos podem ser comparados com os dados experimentais. A partir de então, conclusões acerca da validação ou não dos modelos podem ser feitas através de discussões coletivas, até que a maioria da turma chegue a um consenso sobre a validação ou não de um determinado modelo. Obviamente, que em se tratando de uma turma de ensino médio, a expressão final do alcance para o modelo com resistência do ar, deve ser apenas fornecida pelo docente, sem que os detalhes sejam apresentados, visto que nesta etapa de formação, a solução de uma equação diferencial ordinária de segunda ordem não faz parte do conteúdo programático da turma - embora uma discussão física sobre a força de resistência proporcional à velocidade possa ser realizada. Contudo, em cursos universitários, a depender do período, outras estratégias para se abordar o modelo teórico podem ser adotadas. A eficácia de laboratórios abertos com distintos graus de liberdade 
constitui estudo em andamento com resultados ainda em análise, mas promissores [Melo 2020].

\section{Conclusões e Perspectivas}

Neste trabalho apresentamos uma proposta experimental simples, com brinquedos de baixo custo que produz bons resultados - no sentido de que modelos teóricos são corroborados pelos dados experimentais - para o movimento de um projétil em duas dimensões com resistência do ar, bem como a modelagem matemática, desenvolvida de forma pormenorizada em dois níveis: com e sem resistência do ar.

Em se tratando do modelo com resistência do ar, foi considerada apenas a força de resistência dependente linearmente da velocidade. Ambos os modelos consideraram os projéteis como partículas pontuais e se descolando em duas dimensões. Foram deduzidas expressões analíticas para o alcance dos projéteis em termos dos parâmetros relevantes, como o coeficiente de resistência do ar, o ângulo e o módulo da velocidade de lançamento. Verificamos como os resultados esperados pelos modelos podem ser qualitativamente e quantitativamente discrepantes e em que situações essas discrepâncias podem ser desprezadas.

Os dados obtidos foram comparados com os modelos teóricos, o projétil "bolinha de plástico"e o projétil "dardo com ventosa"tiveram boa concordância com o modelo em que a resistência do ar foi considerada. O projétil "bolinha"foi bem ajustado com um coeficiente de resistência viscosa $\gamma=1,0 \mathrm{~N} /\left(\mathrm{Kgms}^{-1}\right)$, enquanto o projétil "dardo com ventosa"foi bem ajustado com um coeficiente de resistência viscosa 2,0 N/ $\left(\mathrm{Kgms}^{-1}\right)$, o que parece razoável, pois a bolinha, por sua simetria e suas dimensões, deve sofre menor resistência durante o movimento, enquanto o "dardo com ventosa"oferece uma maior área de contato e uma maior assimetria. O projétil "dardo de borracha", no entanto, não apresentou boa concordância com os modelos teóricos, particularmente para ângulos de lançamento menores que $35^{\circ}$, onde o alcance foi muito menor do que o esperado pelo modelo teórico com resistência do ar em relação ao alcance do mesmo projétil para ângulos a partir de $35^{\circ}$.

De posse do equipamento experimental e dos modelos teóricos, ambos foram inseridos em um contexto envolvendo situações problematizadoras, a saber: demonstrações investigativas e laboratórios abertos. Para tal, realizou-se intervenções (duas aulas de cem minutos cada) em uma turma do $3^{\text {o }}$ ano do ensino médio da escola Alexandrino Rocha, localizada no município pernambucano de Bonito [Melo 2019]. Como resultado, constatou-se uma tendência dos estudantes em duvidar dos resultados experimentais e insistir no realismo dos resultados discutidos nos livros didáticos, ou seja, no modelo simplificado. Todavia, acreditamos que tal processo - atividades investigativas - fez com que os estudantes passassem a entender melhor o que é um modelo teórico, na medida em que uma situação de problematização envolvendo a correlação entre teoria e realidade, os leva a refletir sobre o conteúdo estudado. Assim, apesar de num primeiro momento, parecerem não acreditar nas evidências experimentais, assumindo como verdade o modelo teórico, há indícios de mudanças no perfil epistemológico. Ressaltamos o uso do termo indício por se tratar de um projeto ainda em andamento. Assim, como perspectiva (continuidade) propõe-se avaliar mudanças conceituais acerca do grau de realismo dos modelos teóricos em Física. 


\section{REFERÊNCIAS}

BACHELARD, G. A Formação do Espírito Científico. [S.1.]: Editora Contraponto, 2002. 85

BASSANEZI, R. C. Ensino-aprendizagem com modelagem matemática: uma nova estratégia. [S.1.]: Editora Contexto, 2002. 68

BRANDãO, R. V.; ARAUJO, I. S.; VEIT, E. A. A modelagem científica vista como um campo conceitual. Caderno Brasileiro de Ensino de Física, v. 28, n. 3, p. 39, 2011. 68

BUNGE, M. Teoria e Realidade. Rio de Janeiro: Editora Perspectiva, 2009. 68

CARVALHO, A. M. P. d. Calor e temperatura: um ensino por investigação. São Paulo: Editora Livraria da Física, 2014. 68, 69, 81, 85

CARVALHO, A. M. P. d. Fundamentos Teóricos e Metodológicos do Ensino por Investigação. Revista Brasileira de Pesquisa em Educação em Ciências, v. 18, n. 3, p. 30, 2018. 83

CORLESS, R. M. et al. On the LambertW function. Advances in Computational Mathematics, v. 5, n. 1, p. 329-359, Dec 1996. ISSN 1572-9044. 76, 89

GREINER, W. Classical Mechanics: point particles and relativity. New York: Springer Verlag, 2004. 67

HALLIDAY, D.; RESNICK, R.; WALKER, J. Fundamentos de Física. 10å. ed. [S.1.]: LTC, 2016. v. $1.67,69$

KUHN, T. S. A Estrutura das Revoluções Científicas. São Paulo: Perspectiva, 2013. 69

LEMOS, N. A. Mecânica Analítica. São Paulo: Editora Livraria da Física, 2007. 67

MELO, L. F. A. de. Análise didática e experimental de lançamento de projéteis com resistência do ar com a utilização de brinquedos. Dissertação (Monografia de Conclusão de Curso de Graduação) - Universidade Federal de Pernambuco, Caruaru - PE, 2019. 78, 86

MELO, L. F. A. de. Análise Didática e Experimental de Lançamentos de Projéteis com Resistência do Ar com a Utilização de Brinquedos. Projeto de pesquisa em desenvolvimento na UFPE - Centro Acadêmico do Agreste. 2020. 86

NEWTON, I. Principia: princípios matemáticos de filosofia natural: O sistema do mundo. 1a . ed. São Paulo: USP/EDUSP, 2008. 73

SANTOS, B.; ROCHA, Z. da. Introdução ao Software MAXIMA. [S.1.], 2009. Disponível em $<$ http://hostel.ufabc.edu.br/ daniel.miranda/maxima/Maxima_Bruna_Santos_2009.pdf $>$ $(28 / 02 / 2020) .77$

SISTEMA de álgebra computacional Maxima. 2019. Disponível em: <http://maxima. sourceforge.net/pt/index.html>. (28/02/2020). 77

THORMTON, S.; MARION, J. Dinâmica clássica de partículas e sistemas. [S.1.]: Cengage Learning, 2011. 67, 69, 73 


\section{A. Modelo SEM RESistênCIA do AR COMO CASO PARTICUlar do MODELO COM RESISTÊNCIA DO AR}

O modelo sem resistência do ar pode ser recuperado a partir do modelo com resistência linear no limite $\gamma \rightarrow 0$. Entretanto, esse limite não é evidente nas equações (15) e (16), sendo necessário um cálculo cuidadoso, o qual será feito aqui.

Tomando a equação (15), temos,

$$
x(t)=v_{0} \cos \theta\left(\frac{1-e^{-\gamma t}}{\gamma}\right),
$$

usando a regra de L'Hopital é possível mostrar que,

$$
\lim _{\gamma \rightarrow 0}\left(\frac{1-e^{-\gamma t}}{\gamma}\right)=\lim _{\gamma \rightarrow 0} t e^{-\gamma t}=t,
$$

portanto,

$$
x(t) \rightarrow v_{0} \cos (\theta) t,
$$

como esperado, reproduzindo (1) $\operatorname{com} x_{0}=0$, a situação sem resistência do ar.

Tomando, agora, a equação (16), temos,

$$
y(t)=-\frac{g t}{\gamma}+\left(\gamma v_{0} \operatorname{sen} \theta+g\right)\left(\frac{1-e^{-\gamma t}}{\gamma^{2}}\right),
$$

ou melhor,

$$
y(t)=-\frac{g t}{\gamma}+v_{0} \operatorname{sen} \theta\left(\frac{1-e^{-\gamma t}}{\gamma}\right)+g\left(\frac{1-e^{-\gamma t}}{\gamma^{2}}\right) .
$$

Podemos utilizar o limite (23) no segundo termo do lado direito de (24), contudo, o primeiro e o terceiro termos precisam ser combinados antes de tomarmos o limite $\gamma \rightarrow 0$. Para tanto, vamos realizar a expansão de $e^{-\gamma t}$ para obter,

$$
\frac{1-e^{-\gamma t}}{\gamma^{2}}=\frac{t}{\gamma}-\frac{t^{2}}{2}+\frac{t^{3}}{6} \gamma+\ldots
$$

assim,

$$
\begin{aligned}
y(t) & =-\frac{g t}{\gamma}+v_{0} \operatorname{sen} \theta\left(\frac{1-e^{-\gamma t}}{\gamma}\right)+g\left(\frac{1-e^{-\gamma t}}{\gamma^{2}}\right) \\
& =-\frac{g t}{\gamma}+v_{0} \operatorname{sen} \theta\left(\frac{1-e^{-\gamma t}}{\gamma}\right)+g \frac{t}{\gamma}-g \frac{t^{2}}{2}+g \frac{t^{3}}{6} \gamma+\ldots, \\
& =v_{0} \operatorname{sen} \theta\left(\frac{1-e^{-\gamma t}}{\gamma}\right)-g \frac{t^{2}}{2}+g \frac{t^{3}}{6} \gamma+\ldots,
\end{aligned}
$$


portanto, tomando $\gamma \rightarrow 0$, encontramos,

$$
y(t) \rightarrow v_{0} \operatorname{sen}(\theta) t-\frac{g}{2} t^{2}
$$

reproduzindo (2) com $y_{0}=0$.

\section{B. Cálculo Exato do Tempo de Vôo com Resistência do Ar}

Uma expressão analítica pode ser obtida para o tempo de vôo, solução da equação (20), em termos da função $W$ de Lambert. A função $W$ de Lambert é uma função transcendental, definida como a inversa da função,

$$
f(x)=x e^{x},
$$

possuindo aplicações em várias áreas do conhecimento [Corless et al. 1996]. Como pode ser visto na Figura 14a, a função $x e^{x}$ não é injetora no intervalo $[-1 / e, 0]$ do contra-domínio, o que produz dois ramos para a função de Lambert, como pode ser observado na Figura 14b, o ramo $W(x)>-1$, representado em azul, é conhecido como ramo principal de $W$, definido no domínio $[-1 / e,+\infty)$.

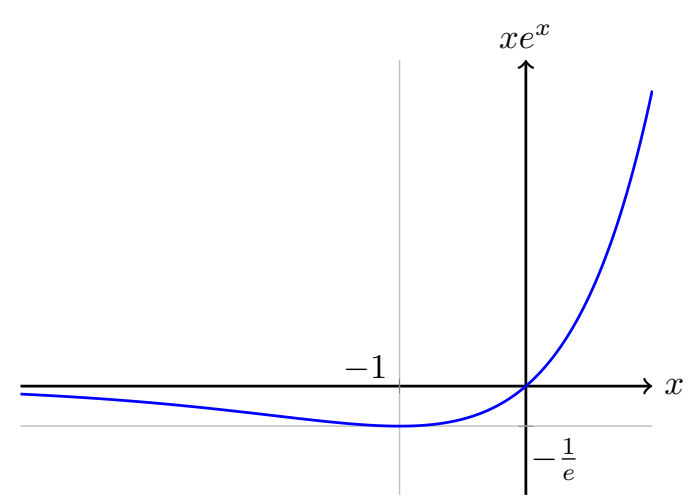

(a)

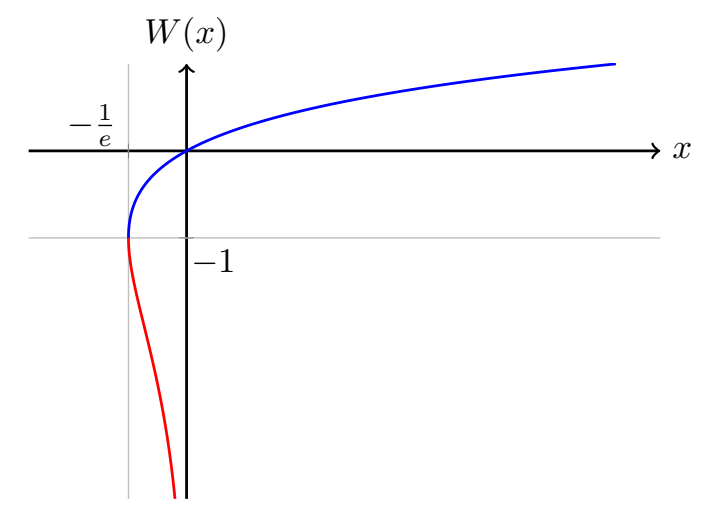

(b)

Figura 14: Função $x e^{x}$ e sua inversa, a função $W$ de Lambert. (a) Função $x e^{x}$. (b) Função $W$ de Lambert obtida por inversão.

Observando que no intervalo $\theta \in\left[0,90^{\circ}\right]$ a função $\operatorname{sen} \theta$ é crescente e pertence ao intervalo $[0,1]$, o menor valor de $A$ em (19) é a unidade, portanto, o argumento de $W$ em (21) está no domínio de seu ramo principal.

Multiplicando (20) por $e^{\tau}$ teremos,

$$
\begin{aligned}
\tau e^{\tau} & =A\left(e^{\tau}-1\right) \\
& =A e^{\tau}-A,
\end{aligned}
$$

donde,

$$
(\tau-A) e^{\tau}=-A
$$


multiplicando por $e^{-A}$ obteremos,

$$
(\tau-A) e^{\tau-A}=-A e^{-A},
$$

portanto, tomando $u \equiv \tau-A$, chegaremos a,

$$
u e^{u}=-A e^{-A} .
$$

Ora, se $W(x)$ é a função de Lambert, então,

$$
W(x) e^{W(x)}=x,
$$

logo,

$$
u=W\left(-A e^{-A}\right),
$$

assim,

$$
\tau=A+W\left(-A e^{-A}\right)
$$

como desejado. 